\title{
Efficiency Evaluation of Urbanization in Western China Based on DEA Model
}

\author{
Bing Yang \\ Faculty of Finance \\ GUFE \\ Guiyang, P. R. China \\ 649747376@qq.com
}

\author{
Chenggang Li \\ Faculty of Finance \\ GUFE \\ Guiyang, P. R. China; \\ lichenggang603@126.com
}

\author{
Min Li \\ Faculty of Finance \\ GUFE \\ Guiyang, P. R. China; \\ 2431605045@qq.com
}

\begin{abstract}
Studying on the efficiency of urbanization in the western region is conducive to the promotion of urbanization construction in the western region. Taking twelve provinces, municipalities and autonomous regions in the western region as an example, from the input-output perspective, this paper constructs the urbanization efficiency index system, and use DEA model to estimate the comprehensive efficiency, pure technical efficiency and scale efficiency value of western region urbanization from 2010 to 2015 . The empirical results show that, for the comprehensive technical efficiency value, between 2010 and 2013, the comprehensive technical efficiency of the urbanization in western region shows a downward trend. It shows that the urbanization in the western region is unreasonable for the resource allocation and resource use. From 2013 to 2015, the comprehensive technical efficiency of the urbanization in western region appears the overall upward fluctuation. This shows that the urbanization construction in the western region has a reasonable improvement on the allocation of resources and the efficiency of resource use. The pure technical efficiency of the urbanization in western region shows the overall upward trend between 2010 and 2015. The scale technical efficiency of the urbanization in western region presents the overall decline between 2010 to 2015. This shows that the overall optimal scale of urbanization in western region is deteriorating.
\end{abstract}

Keywords-Urbanization efficiency; DEA model; Western region

\section{INTRODUCTION}

With the rapid development of economy and the rapid development of urbanization, the efficiency of urbanization has become the focus of economic development. Urbanization is a historical process from the traditional agricultural society to the modern urban society, and represents the fundamental change of the social and economic structure and the great development. Implementing the strategy of urbanization and promoting the process of urbanization is the unification of a country or region to gradually get rid of the underdeveloped state and realize the tasks and means of modernization [1]. The economy of the western region is relatively backward, and urbanization has been the focus of government attention, and the efficiency of urbanization is the most important. Studying the efficiency of urbanization in the western region will help promote the urbanization construction in the western region and raise the urbanization level [2].
Taking twelve provinces, municipalities and autonomous regions in the western region as an example, this paper uses the DEA model based on the three point method to study the efficiency of urbanization in the western region. According to the relative efficiency analysis of input and output, the comprehensive technical efficiency, pure technical efficiency and scale technical efficiency of urbanization in twelve provinces, municipalities directly under the central government and autonomous regions are calculated. And the efficiency values of each province, municipality directly under the central government and autonomous region, the efficiency of urbanization in the western region are evaluated.

\section{Model SETting}

DEA model is also known as data envelopment analysis method, is put forward in 1978 by the famous scientist Charnes, Cooper and Rhodes [3], and mainly is used for the evaluation of the relative effect between in the same department. In this paper, we use the neutral class method in the DEA model based on the three point method, and the model is defined as follows:

If there are $\mathrm{n}$ decision units, each decision unit has $\mathrm{m}$ inputs, then inputs are $\mathrm{xj}$ :

$$
\left.x_{j}=\left(x_{1 j}, x_{2 j}, \cdots x_{m j}\right)^{T}\right\rangle 0, j=1,2, \cdots, n
$$

According to the $\mathrm{m}$ inputs, each decision element corresponds to the $\mathrm{s}$ item output, and the output $\mathrm{y}$ is:

$$
\left.\boldsymbol{y}_{j}=\left(\boldsymbol{y}_{1 j}, \boldsymbol{y}_{2 j}, \cdots, \boldsymbol{y}_{s j}\right)^{T}\right\rangle 0, \boldsymbol{j}=1,2, \cdots, n
$$

According to the input vector $\boldsymbol{x}_{j}=\left(\boldsymbol{x}_{1 j}, \boldsymbol{x}_{2 j}, \cdots \boldsymbol{x}_{\boldsymbol{m} j}\right)^{T}>O$ and the output vector $\boldsymbol{y}_{j}=\left(\boldsymbol{y}_{1 j}, \boldsymbol{y}_{2 j}, \cdots, \boldsymbol{y}_{s j}\right)^{\boldsymbol{T}}>O$, the technical efficiency and technical efficiency of the input are calculated respectively, and then the comprehensive technical efficiency is calculated [4-7]. Given the technical efficiency of $\theta_{i}$ as the first $\mathrm{i}$ decision unit, the maximum technical efficiency of the decision making unit $(\mathrm{x} 0, \mathrm{y} 0)$ is calculated from the input point of view as $(\mathrm{x} 0, \mathrm{y} 0)$ : 
$\max \theta$

$$
\text { s.t. }\left\{\begin{array}{c}
\sum_{j=1}^{n} \lambda_{j} x_{j} \leq \theta_{i} x_{O} \\
\sum_{j=1}^{n} \lambda_{j} y_{j} \geq y_{O} \\
\sum_{j=1}^{n} \lambda_{i}=1, \forall \lambda_{i} \geq O
\end{array}\right.
$$

Given the technical efficiency of $\theta_{i}$ as the first $\mathrm{i}$ decision unit, the maximum technical efficiency of the decision unit $(\mathrm{x} 0$, $\mathrm{y} 0)$ is calculated from the point of view of output as $(\mathrm{x} 0, \mathrm{y} 0)$ :

$$
\begin{aligned}
& \max \delta \\
& \text { s.t. }\left\{\begin{array}{c}
\sum_{j=1}^{n} \lambda_{j} x_{j} \leq x_{O} \\
\sum_{j=1}^{n} \lambda_{j} y_{j} \geq \delta y_{O} \\
\sum_{j=1}^{n} \lambda_{i}=1, \forall \lambda_{i} \geq O
\end{array}\right.
\end{aligned}
$$

Assuming xi and yi respectively is I of the decision-making unit of input and output, then calculating the comprehensive technical efficiency and pure technical efficiency according to the technical efficiency of input and output. $x$ and $y$ respectively for the column vector input unit column vector and the output unit, $\theta$ is the first i comprehensive technical decision making unit rate:

$$
\begin{gathered}
\max \lambda \theta_{i} \\
\text { s.t. }\left\{\begin{array}{c}
\gamma y \geq \theta_{i} \boldsymbol{y}_{i} \\
\boldsymbol{x}_{\boldsymbol{i}} \geq \boldsymbol{x} \lambda \\
\lambda \geq 0
\end{array}\right.
\end{gathered}
$$

When $\boldsymbol{n}_{1}=\lambda=1$, comprehensive technical efficiency $\max \lambda \theta_{i}$ is pure technical efficiency.

\section{DEA COMPREHENSIVE EFFICIENCY CALCULATION}

This paper uses the provincial panel data of twelve provinces, municipalities and autonomous regions from 2010 to 2015. Data are from the statistical yearbook, the website of the Bureau of statistics and the National Bureau of statistics website. The calculation of input and output efficiency by using DEA model, we must first determine the input variables and output variables. The input variables are the urban population (million) and urban fixed asset investment (100 million yuan), and the output variables are GDP (100 million yuan). Input and output variables and factors are shown in Table 1.

TABLE I DATA VARIABLE

\begin{tabular}{|c|c|}
\hline Input variable & Output variable \\
\hline $\begin{array}{c}\text { Urban population (million) } \\
\begin{array}{c}\text { Urban fixed asset investment (100 } \\
\text { million yuan) }\end{array}\end{array}$ & $\begin{array}{c}\text { Gross Regional Product } \\
\text { (100million yuan) } \\
\text { Per capita GDP }\end{array}$ \\
\hline
\end{tabular}

Using the software Deap2.1 to calculate the comprehensive technical efficiency of the western provinces, the results are shown in Table 2.

TABLE II COMPREHENSIVE TECHNICAL EFFICIENCY

\begin{tabular}{|c|c|c|c|c|c|c|}
\hline Province & $\mathbf{2 0 1 0}$ & $\mathbf{2 0 1 1}$ & $\mathbf{2 0 1 2}$ & $\mathbf{2 0 1 3}$ & $\mathbf{2 0 1 4}$ & $\mathbf{2 0 1 5}$ \\
\hline Sichuan & 0.81 & 0.80 & 0.83 & 0.86 & 0.87 & 0.89 \\
\hline Guizhou & 1.00 & 0.87 & 0.89 & 0.95 & 1.00 & 1.00 \\
\hline C Qing & 0.86 & 0.89 & 0.87 & 0.90 & 0.94 & 0.99 \\
\hline Yunnan & 1.00 & 1.00 & 1.00 & 1.00 & 0.95 & 0.87 \\
\hline Tibet & 1.00 & 1.00 & 1.00 & 1.00 & 1.00 & 1.00 \\
\hline Shanxi & 0.86 & 0.83 & 0.81 & 0.78 & 0.80 & 0.72 \\
\hline Gansu & 0.58 & 0.54 & 0.53 & 0.56 & 0.58 & 0.60 \\
\hline Qinghai & 1.00 & 0.80 & 0.71 & 0.78 & 0.77 & 0.78 \\
\hline Ningxia & 0.97 & 0.95 & 0.85 & 0.90 & 0.83 & 0.86 \\
\hline Xinjiang & 1.00 & 1.00 & 0.98 & 1.00 & 0.99 & 0.87 \\
\hline Guangxi & 0.64 & 0.60 & 0.60 & 0.62 & 0.63 & 0.63 \\
\hline I M golia & 1.00 & 1.00 & 0.87 & 0.92 & 0.85 & 1.00 \\
\hline Average & 0.89 & 0.85 & 0.83 & 0.86 & 0.85 & 0.85 \\
\hline Effective & 6 & 4 & 2 & 3 & 2 & 3 \\
\hline As Can be seen from
\end{tabular}

As can be seen from Table 2, from 2010 to 2015, only the comprehensive technical efficiency of urbanization in Tibet was effective, and the efficiency was 1 . Followed by the Yunnan region, from 2010 to 2012, in the first four years of urbanization, the comprehensive technical efficiency of 1, are effective. And the town of Xinjiang area and Guizhou area and Inner Mongolia area of comprehensive technical efficiency values of three years to reach 1 between 2010 and 2015, Qinghai urban areas only in the comprehensive technical efficiency value of 1 in 2010, 6 provinces and towns remaining comprehensive technical efficiency values were less than 1 , the overall technical efficiency is invalid. This means that these provinces and cities in the input and output there are still a large number of waste of resources [8].

TABLE III PURE TECHNICAL EFFICIENCY IN WESTERN CHINA

\begin{tabular}{|c|c|c|c|c|c|c|}
\hline Province & $\mathbf{2 0 1 0}$ & $\mathbf{2 0 1 1}$ & $\mathbf{2 0 1 2}$ & $\mathbf{2 0 1 3}$ & $\mathbf{2 0 1 4}$ & $\mathbf{2 0 1 5}$ \\
\hline Sichuan & 1.00 & 1.00 & 1.00 & 1.00 & 1.00 & 1.00 \\
\hline Guizhou & 1.00 & 0.89 & 0.90 & 0.96 & 1.00 & 1.00 \\
\hline C Qing & 0.88 & 0.99 & 0.97 & 1.00 & 1.00 & 1.00 \\
\hline Yunnan & 1.00 & 1.00 & 1.00 & 1.00 & 0.99 & 0.89 \\
\hline Tibet & 1.00 & 1.00 & 1.00 & 1.00 & 1.00 & 1.00 \\
\hline Shanxi & 0.86 & 0.88 & 0.89 & 0.89 & 0.90 & 0.73 \\
\hline Gansu & 0.60 & 0.54 & 0.54 & 0.57 & 0.59 & 0.61 \\
\hline Qinghai & 1.00 & 0.96 & 0.98 & 1.00 & 1.00 & 1.00 \\
\hline Ningxia & 1.00 & 1.00 & 1.00 & 1.00 & 1.00 & 1.00 \\
\hline Xinjiang & 1.00 & 1.00 & 1.00 & 1.00 & 1.00 & 0.88 \\
\hline Guangxi & 0.64 & 0.60 & 0.62 & 0.63 & 0.66 & 0.64 \\
\hline I M golia & 1.00 & 1.00 & 1.00 & 1.00 & 1.00 & 1.00 \\
\hline Average & 0.91 & 0.90 & 0.91 & 0.92 & 0.93 & 0.90 \\
\hline Effective & 8 & 6 & 6 & 8 & 8 & 7 \\
\hline
\end{tabular}


According to the input variables for the western region twelve provinces, municipalities and autonomous regions of the urban population (million) and urban fixed asset investment (100 million yuan), the output variables for the region's GDP (100 million yuan). Through the software to calculate the pure technical efficiency of the western provinces, the results are shown in Table 3.

As can be seen from Table 3, from 2010 to 2015, the pure technical efficiency of urbanization in Sichuan, Tibet, Ningxia and Inner Mongolia was effective, with efficiency values of 1.Second, the value of pure technical efficiency of urbanization in Xinjiang has 5 years, and the value is 1 , all of which are valid in six years. Moreover, the pure technical efficiency of urbanization in Yunnan and Qinghai areas has been valid for four years, with an efficiency value of 1.Finally, the urbanization in Chongqing and Guizhou has three years of pure technical efficiency and effectiveness [9]. The technical efficiency values of the remaining provinces are less than 1, and the pure technical efficiency is invalid. This means that these provinces and cities in the input and output there are still a large number of waste of resources.

According to the input variables for the western region twelve provinces, municipalities and autonomous regions of the urban population (million) and urban fixed asset investment (100 million yuan), the output variables for GDP (100 million yuan) and per capita GDP (yuan / person). The scale and technical efficiency of urbanization in Western China are calculated by software, as shown in Table 4.

TABLE IV SCALE TECHNICAL EFFICIENCY IN WESTERN CHINA

\begin{tabular}{|c|c|c|c|c|c|c|}
\hline Province & $\mathbf{2 0 1 0}$ & $\mathbf{2 0 1 1}$ & $\mathbf{2 0 1 2}$ & $\mathbf{2 0 1 3}$ & $\mathbf{2 0 1 4}$ & $\mathbf{2 0 1 5}$ \\
\hline Sichuan & 0.81 & 0.80 & 0.83 & 0.86 & 0.87 & 0.89 \\
\hline Guizhou & 1.00 & 0.99 & 0.99 & 0.99 & 1.00 & 1.00 \\
\hline C Qing & 0.98 & 0.90 & 0.90 & 0.90 & 0.94 & 0.99 \\
\hline Yunnan & 1.00 & 1.00 & 1.00 & 1.00 & 0.95 & 0.99 \\
\hline Tibet & 1.00 & 1.00 & 1.00 & 1.00 & 1.00 & 1.00 \\
\hline Shanxi & 1.00 & 0.94 & 0.90 & 0.88 & 0.89 & 1.00 \\
\hline Gansu & 0.97 & 0.99 & 0.99 & 0.99 & 1.00 & 0.99 \\
\hline Qinghai & 1.00 & 0.84 & 0.72 & 0.78 & 0.77 & 0.78 \\
\hline Ningxia & 0.97 & 0.95 & 0.85 & 0.90 & 0.83 & 0.86 \\
\hline Xinjiang & 1.00 & 1.00 & 0.98 & 1.00 & 0.99 & 0.99 \\
\hline Guangxi & 1.00 & 0.99 & 0.98 & 0.99 & 0.96 & 0.99 \\
\hline I M golia & 1.00 & 1.00 & 0.87 & 0.92 & 0.85 & 1.00 \\
\hline Average & 0.97 & 0.95 & 0.92 & 0.93 & 0.92 & 0.95 \\
\hline Effective & 8 & 4 & 2 & 3 & 3 & 4 \\
\hline
\end{tabular}

As can be seen from Table 4, only the scale and technical efficiency of urbanization in Tibet in 2010 and 2015 are effective, and the efficiency values are 1. Followed by urbanization in Yunnan in 2010 to 2013, four years of scale, technical efficiency value of 1 , are valid [10]. Moreover, the urbanization in Guizhou, Xinjiang and Inner Mongolia has been six years from 2010 to 2015, with a scale of three years and a technical efficiency of 1 . Finally, the scale of urbanization in Shaanxi area have two years of technical efficiency value is 1 , the scale of technical efficiency in 2010 to 2015 this six years only a year in Gansu town was 1, the size of other provinces urbanization technical efficiency values are invalid. This means that these provinces and cities in the input and output there are still a large number of waste of resources.

\section{URBANIZATION EFFICIENCY TREND ANALYSIS}

Through the estimated urbanization comprehensive technical efficiency, pure technical efficiency and scale technical efficiency of twelve provinces, municipalities and autonomous regions in western region, the average from 2010 to 2015 each year a variety of technical efficiency in western region urbanization value can be obtained. The urbanization trend of the comprehensive technical efficiency, pure technical efficiency and scale technical efficiency are shown in Fig 1.

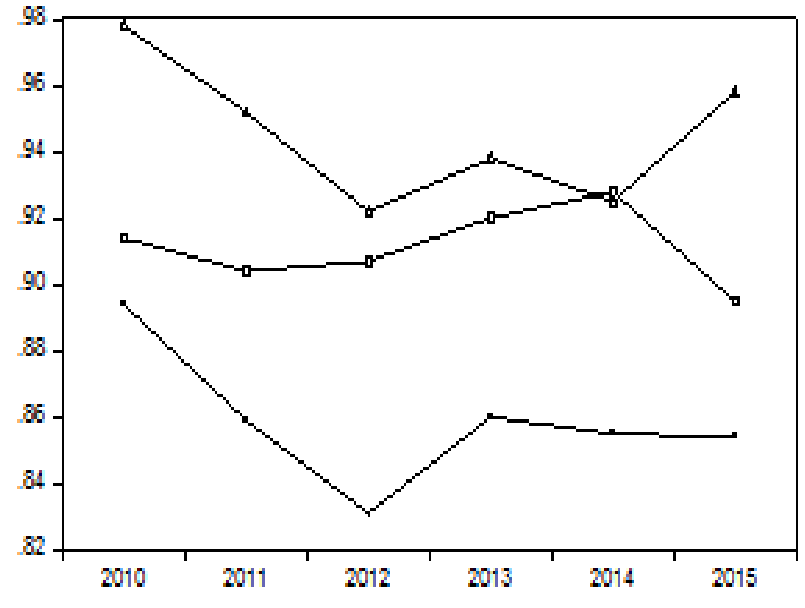

Fig. 1. Urbanization efficiency trend map

As can be seen from Fig 1, from 2010 to 2015, the overall technical efficiency of urbanization in the western region showed a downward trend as a whole. From 2010 to 2014, the pure technical efficiency in the urbanization of western region is gradually rising, the pure technical efficiency of urbanization is mainly because of the government management and technology and other factors influence the efficiency of investment in the western region of the country with vast resources and technology, pure technical efficiency makes the western region urbanization continues to increase [11]. From 2010 to 2015 in the western part of the scale of the technical efficiency of urbanization in a whole range of technical efficiency scale of urbanization is mainly affected by the scale factor of a town, from 2010 to 2014 the urbanization scale technical efficiency in the western region has declined, mainly because the gap between the western region and regional economy overall, urban scale has not reached the optimal.

\section{CONCLUSION AND POLICY RECOMMENDATION}

In this paper, DEA method is used to study the efficiency of urbanization in Western China by using panel data of twelve provinces, municipalities and autonomous regions from 2010 to 2015 years in Western China. This paper selects the urban population and urban fixed asset investment as input variables, and GDP and per capita GDP as the output variables. This 
paper uses DEA method to calculate the comprehensive technical efficiency, pure technical efficiency and scale technology efficiency. The calculation results show that, from 2010 to 2015, the comprehensive technical efficiency of urbanization in the western region shows a downward trend as a whole. The pure technical efficiency of urbanization in the western region increased from 2010 to 2015. Seen from the size of the urbanization technical efficiency in western region, in 2010, the urbanization scale effective areas reach 8 , and are mainly concentrated in Tibet, Yunnan, Xinjiang and other regions; in 2015, the urbanization scale effective areas drop to 4.

Based on the empirical results, we propose the following policies to increase the urbanization efficiency in western region:

Firstly, vigorously promote the economic development of the western region. To improve the efficiency of urbanization, we must first develop the economy, increase the per capita income of the local residents, raise the income level of the residents, and increase the GDP of the region. There are many ways to raise the per capita income of the residents. The government can introduce enterprises, increase the employment income of local residents, and spare less labor. In the western region, the education level of most residents is not high. Therefore, when introducing enterprises, we can choose labor-intensive enterprises such as Foxconn to improve the income of residents and promote regional economic development.

Secondly, improve the urbanization development mode. Because the economy development in western region is different from the central and eastern region, the urbanization development mode of western region is special. The government of western region should optimize the industrial structure, and promote industrial upgrading. The government also should develop the cultural industries which have characteristics of the Western region.

Third, raise the level of urbanization in the western region. The government can introduce the corresponding policies to encourage the rural population migration, urbanization and new rural construction coordination, so that more farmers are willing to become citizen, and this will lead to increase the proportion of urban population, improve the level of urbanization, and then improve the urbanization level of efficiency.

Finally, promote the development of rural urbanization. As the center of the province, the provincial capital should improve the integration level of the economic development between the capital city and the nearby city, actively cooperate with the local development policy, promote urban and rural development, and improve the development of rural urbanization.

\section{REFERENCES}

[1] Liu Fan, Liu Donghuang, Liu Xinbo. Study on mutual promotion effect of urbanization and industrial structure upgrading--Based on DEA model analysis [J]. Industrial Economic Forum, 2016, (3): 653-658.

[2] Li Xiaomin. Study on the urbanization efficiency of the three major urban agglomerations in the Yangtze River Economic Zone [D]. Chongqing: Southwestern University, 2016.

[3] A Charnes, W W Cooper, E Rhodes. Measuring the efficiency of decision making units [J]. European Journal of Operational Research 1978, 2 (6): 429-444.

[4] J Johnes. DEA and its Application to the Measurement of Efficiency in Higher Education [J]. Social Science Electronic Publishing, 2015, 25 (3) 273-288.

[5] N Ederer. Evaluating capital and operating cost efficiency of offshore wind farms: A DEA approach [J]. Renewable \& Sustainable Energy Reviews, 2015, 42: 1034-1046.

[6] G Vlontzos, S Niavis, B Manos. A DEA approach for estimating the agricultural energy and environmental efficiency of EU countries [J]. Renewable \& Sustainable Energy Reviews, 2014, 40: 91-96.

[7] Fang Chaoping, Wu Shidai, Zhang Tingyu. Measurement of urbanization efficiency level based on DEA-Malmquist method: a case study of Fujian province [J]. Journal of Hainan Normal University (Natural Science Edition), 2016, 29 (3): 321-326.

[8] Liu Xiping. Study on the efficiency of urbanization in China based on DEA-Malmquist index method [J]. Journal of Hubei University of Economics, 2017, 15 (1): 32-38.

[9] Wan Qing, Wu Chuanqing, Zeng Juxin. Chinese city cluster urbanization efficiency and influencing factors $[\mathrm{J}]$. China Population, Resources and Environment, 2015, 25 (2): 66-74.

[10] Huang Yongbin, Dong Suocheng, Bai Yongping. Spatial and temporal characteristics of the relationship between urban compactness and urban efficiency in China [J]. China Population, Resources and Environment, 2015, 25 (3): 64-73

[11] Li Ping, Li Ying. Development efficiency and institutional innovation path of urbanization in China [J]. Quantity, Economy, Technology and Economy, 2016, (5): 30-43. 